\title{
PARALLEL CONNECTED INVERTER FOR FUEL CELL SYSTEM
}

\author{
M.A.A.Younis ${ }^{1}$, N. A. Rahim ${ }^{2}$ and S. Mekhilef ${ }^{3}$ \\ ${ }^{1}$ EE Dept., unisel, selangor, malaysia \\ ${ }^{2,3}$ EE dept. um, 50603, kuala lumpur,malaysia. \\ E-Mail:mahmoud@unisel.edu.my
}

\begin{abstract}
This paper presents the design and analysis of a new configuration of parallel connected inverter suitable for fuel cell system application. The configuration consists of $\mathrm{dc} / \mathrm{dc}$ converter and parallel three-phase dc/ac inverter. Series resistors added to the inverter output to maintain same current in each inverter of the two parallel inverters, and to reduce the circulating current in the parallel inverters to minimum. Third harmonic injection PWM (THIPWM) reduces the total harmonic distortion and to make maximum use of the voltage source. DSP was used to create the THIPWM and the control algorithm for the converter. PID controller is applied on the full-bridge $\mathrm{dc} / \mathrm{dc}$ converter side to maintain the ac voltage to the required level. Experimental results have been shown to validate the proposed system.
\end{abstract}

Index Terms - three-phase inverter, Third harmonic injection PWM, inverters parallel connection, fuel cell system.

\section{INTRODUCTION}

In recent years, many concerns have been raised over the fossil fuel-electricity generation, since it pollutes our environment and depletes the energy supply [1]. Alternative energy sources, such as fuel cells, gain a lot of attention because it is friendly to the environment and flexible for installation. Fuel cells are currently considered attractive power sources for portable power applications in civilian arenas because of their superior power densities, silent operation and non-polluting nature [2].However, this type of sources provides unstable dc voltage which needs to be stabilized and converted to ac voltage to be suitable for ac load application.. With PWM control technologies, ac side of the grid connected inverter has the abilities of controllable power factor, sinusoidal output currents and bi-directional power transfer. [3][4] The third harmonic injection method to control the power factor of the inverter output current used for three-phase inverter. However, it is very difficult to generate the right third harmonic amplitude [5] [6]. In hysteresis control the switching frequency varies significantly according to the power level and the dc link [7] [8].
The fuel cells system typically consists of a dc/dc converter to boost the source voltage to a higher level and a dc/ac inverter. Several variations of this scheme have been proposed in the literature [9] [10], each presenting advantages and disadvantages. Isolated $\mathrm{dc} / \mathrm{dc}$ converter became a hot topic in the last decade because of their wide application in green power application which includes solar, wind, geothermal, ocean energy and fuel cell. The front end of the isolated dc-dc converter, which is full bridges have been seen in most applications. Compared with half bridge, full bridge will have less current stress and doubled input voltage utilization.

\section{SYSTEM BLOCK DIAGRAM}

The block diagram of the system is shown in Figure 1. The dc voltage produced by the dc power supply is converted to a high-frequency train of positive and negative pulse pairs by the full-bridge converter, which is controlled by the phase-shift modulation technique. The widths of the positive and negative pulses in each pair are equal in attempt to avoid saturation of the high-frequency transformer. The high-frequency transformer isolates the dc source from the grid and steps up the amplitudes of the pulses to the level required for the successful control of grid voltage. As the local average of the pulse train on the secondary-side of the transformer is zero, rectification through the diode-rectifier bridge is used to produce a train of positive pulses of nonzero local average. The rectified voltage ripple reduces to minimum value using high capacitor value. The Six-step modulation uses a sequence of six switches patterns for three-phase fullbridge inverter to generate a full cycle of three-phase voltages.

\section{ISOLATED DC/DC CONVERTER}

The isolated dc/dc converter shown in Figure 2 consist of two stages where the dc power converted to a highfrequency train of positive and negative pulse pairs by inverter stage. The produced voltage stepped up using high frequency transformer followed by full bridge rectifier. The high frequency transformer employed to realize isolation between the dc source and the grid, and to get high dc voltage on the converter output. 


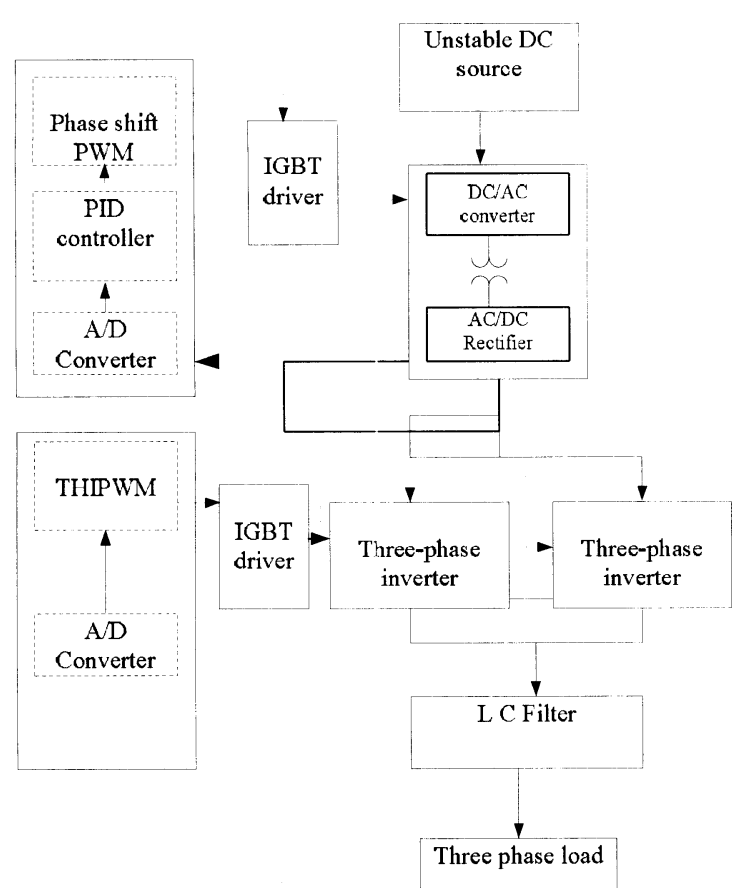

Figure 1. The block diagram of the grid-connected system

The full-bridge inverter's operation can be divided into four modes: two modes in positive load current period and two modes in negative load current period. Figure 3 shows the dc/dc converter operational modes. A Proportional-Integral-Derivative controller or PID controller is a common used controller in industrial control applications. To tune the PID for optimal operation the tuning method applied is Ziegler and Nichols method which based on the system's open-loop step response [11].

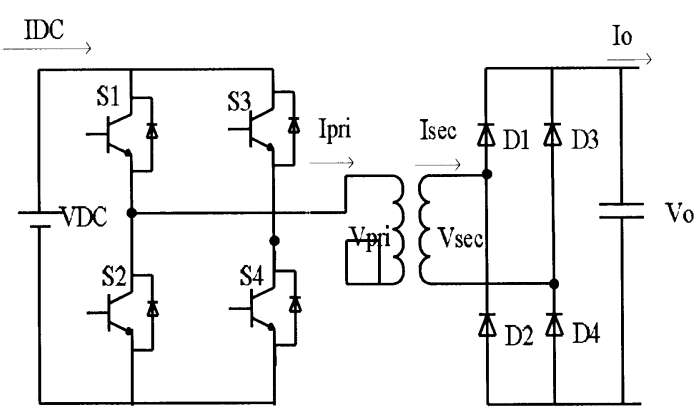

Figure 2. Isolated dc/dc converter

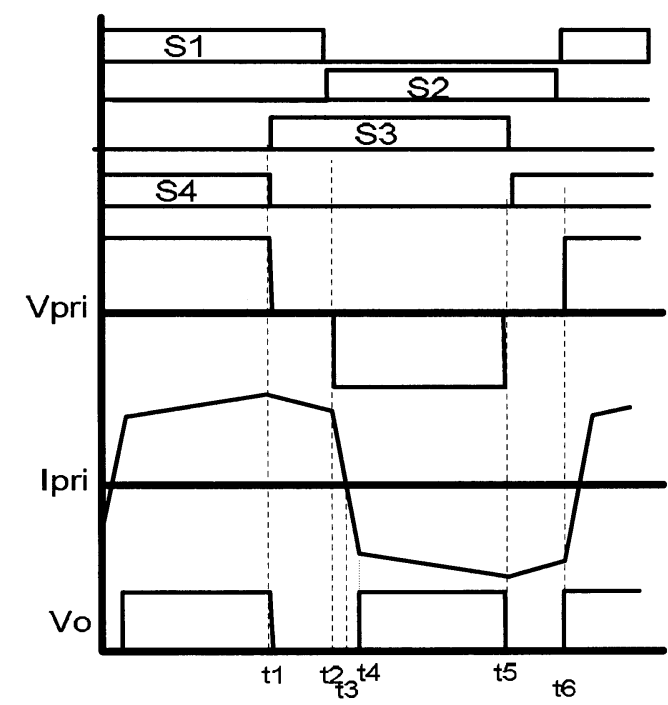

Figure 3. Modes of operational for $\mathrm{dc} / \mathrm{dc}$ converter.

\section{THREE PHASE INVERTER}

A standard three-phase grid-connected inverter is shown in Figure 4 consisting of six controlled switches such as IGBT. In this converter, the line currents can be shaped to be sinusoidal at a unity power factor, as well as the output ac voltage can be regulated at a desired value. The inverter is connected to the grid through three LC filters. THIPWM employed to make full use of the input voltage with minimum harmonic distortion in the output voltage and current.

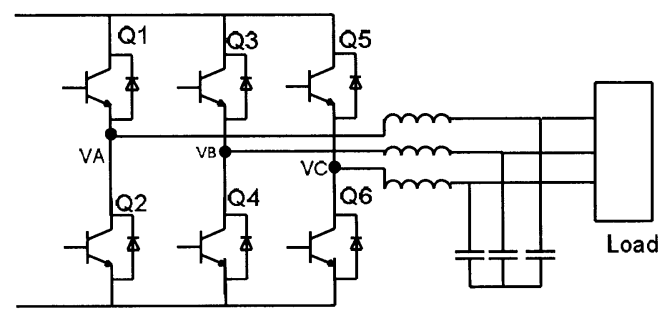

Figure 4 Three-phase inverter

The modulating signal is generated by injecting the third harmonic component to the $50 \mathrm{~Hz}$ fundamental component as given in equation 1 .

$$
v_{r}=1.15 \sin \omega t+0.19 \sin 3 \omega t
$$

Using the modulator given in equation 1 will maintain the peak voltage equal to the dc voltage.

The Embedded Target for the TI C2000 used to construct system models and real-time control algorithms within the SIMULINK environment, using blocks from the SIMULINK block library. Target for TI C2000 used along with Link for Code Composer Studio to automate code generation, execution, and communication with TI evaluation boards by inserting blocks for optimized functions, together with the appropriate board 


\section{5th International Multi-Conference on Systems, Signals and Devices}

peripherals, into the model [12]. Three ePWM blocks used to obtain three-phase THIPWM for the three-phase inverter. Each ePWM block generate switching signal for one leg of the inverter as shown in Fig.5.

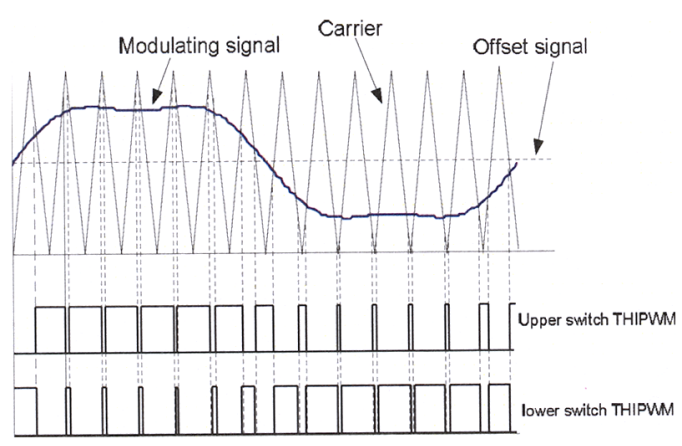

Figure 5 Generation of THIPWM

The modulating signal data generated using equation 1 and saved in lookup table. The carrier is provided by the ePWM block by applying suitable PWM setting. The carrier frequency is calculated from the following equations when the counter setting is up/down.

$$
\begin{gathered}
T P W M=2(T B P R L) \times T T B C L K) \\
F P W M=\frac{1}{T P W M} \\
T B C L K=\frac{S Y S C L K O U T}{H S P C L K L) I V \times C L K D I V}
\end{gathered}
$$

Where TPWM is the PWM interval, TBRD is the value saved in TBPRD register, TTBCLK is the time of one clock cycle, and FPWM is the carrier frequency. The clock frequency is calculated using equation 4 where SYSCLKOUT is the synchronous clock frequency which $100 \mathrm{MHz}$, HSPCLKDIV is High Speed Time-base Clock Prescale Bits which to be selected as one of the following values $(1,2,4,6,8,10,12$, or 14). CLKDIV is Time base Clock Prescale Bits which to be selected as one of the following values $(2,2,4,16,32,64$, or 128$)$. The PWM cycle (TPWM) shown in Figure 6.

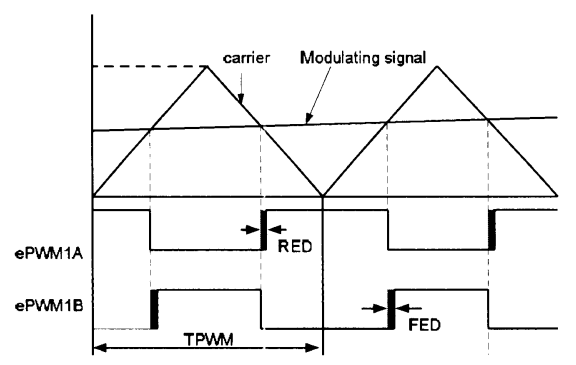

Figure 6 one switching interval
To prevent a short circuit in the dc link of IGBT voltage source PWM converters, the dead time period during which both the upper and lower IGBT's of the inverter phase leg are off, need to be inserted in switching signals[15]. The dead time can cause waveform distortion and the fundamental voltage loss of the converter.

To create dead time for the switches on the same leg the dead band (DB) module is used. The DB module supports independent values for rising edge (RED) and falling edge (FED) delays. The amount of delay is programmed using the dead band rising edge (DBRED) and dead band falling edge (DBFED) memory-mapped registers. These are 10-bit registers and their value represents the number of TBCLK periods a signal edge is delayed by. The formulas to calculate FED and RED respectively are as follow [13]:

$$
\begin{aligned}
& F E D=D B F E D \times T T B C L K \\
& R E D=D B R E D \times T T B C L K
\end{aligned}
$$

\section{PARALLEL CONNECTION}

In parallel operation, two or more inverters are tied together to share the load. In this paper, a system of two units will be discussed for convenience. Figure 7 shows two inverters which are directly connected both at both input and output ends. The parallel connection done for the two bridges such that the dc side filters and the ac side filter are common for the two parallel inverters. Inverters with different ratings some times patrolled, it is desirable to share the currents according to the rated power of each module. If the bridges inverter used nonidentical IGBT's, Current Sharing and Circulating Current are to be considered.

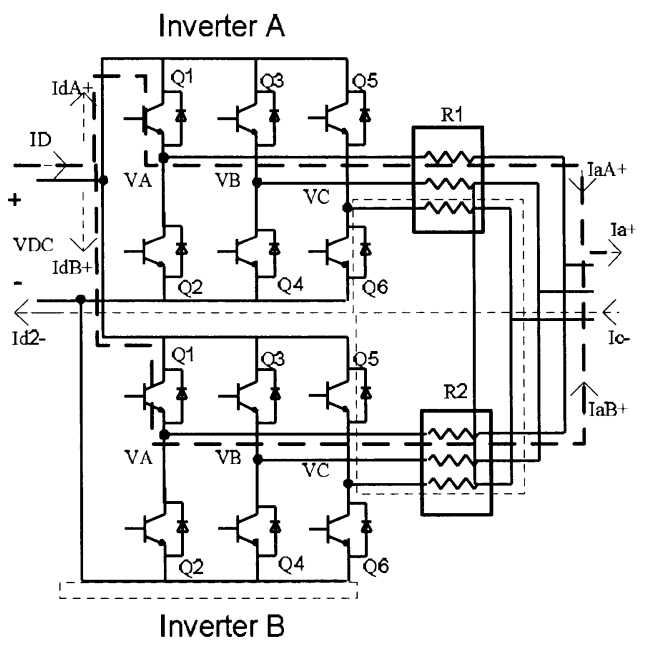

Figure 7 parallel connection of two three-phase inverters

To study the Current Sharing and Circulating Current one mode of operation is to be taken Figure 8 shows the mode of operation when the current IdA+ flowing through Q1A and Q1B, however the current IdA- flowing back to the 
source through Q6A and Q6b. the Figure shows the current sharing between Q1A and Q1B with two series resistors included.

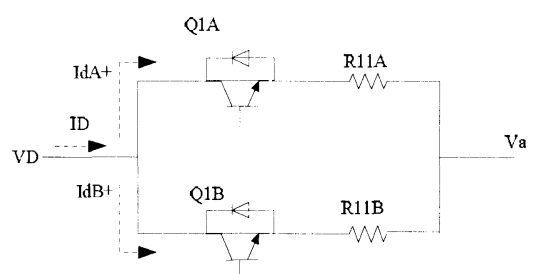

Figure 8 circulating current during one switching cycle

The current sharing depends on the IGBT's Q1A and Q1B, If VCE1A not equal to VCE1B as a result IdA+ will not be equal to $\mathrm{IdB}+$. To maintain similar current sharing between the two inverters series resistor R1 and R2 added between each leg of the six legs and the common point as shown in Figure 8. R1 box consists of three resistors $\mathrm{R} 11, \mathrm{R} 12$, and R13. Similarly R2 consists of R21, R22, and R23. Including the resistances R11A and $\mathrm{R} 11 \mathrm{~B}$ as shown in Figure 8 must satisfy the following condition:

$$
\begin{gathered}
V_{C E 1 A}+I_{d A}^{+} \cdot R_{11 A}=V_{C E 1 B}+I_{d B}^{+} \cdot R_{11 B} \\
\text { let. } \\
I_{d A}^{+}=I_{d B}^{+}=\frac{I_{D}}{2} \\
\frac{I_{D}}{2}\left(R_{11 A}-R_{11 B}\right)=V_{C E 1 B}-V_{C E 1 A} \\
\text { or } \quad R_{11 A}=\frac{2\left(V_{C E 1 B}-V_{C E 1 A}\right)}{I_{D}}+R_{11 B}
\end{gathered}
$$

To select the right value of $\mathrm{R} 1$ and $\mathrm{R} 2$ each of them suppose to be much smaller than the load resistance. The circuit will experience similar current sharing in all the modes of operation as a result the circulating current will be small.

\section{RESULT AND DISCUSSION}

A parallel connected system was designed and implemented to verify the above discussion. The parameters of the system are as follow.

IGBT for inverter a is SSG60N60 with $\mathrm{V}_{\mathrm{CE}(\mathrm{ON})}=1.75 \mathrm{~V}$.

IGBT for inverter $\mathrm{b}$ is IRGP50B60PD1 with $\mathrm{V}_{\mathrm{CE}(\mathrm{ON})}=$ $2 \mathrm{~V}$.

$\mathrm{LC}$ at inverter output side $\mathrm{L}=5 \mathrm{mH} \quad \mathrm{C}=10 \mu \mathrm{F}$

Carrier frequency $=4.5 \mathrm{kHz}$

The connection of two parallel inverters with different IGBT's ratings and without the resistor connection produces unbalance currents at the output of each inverter side as shown in Figure 9.

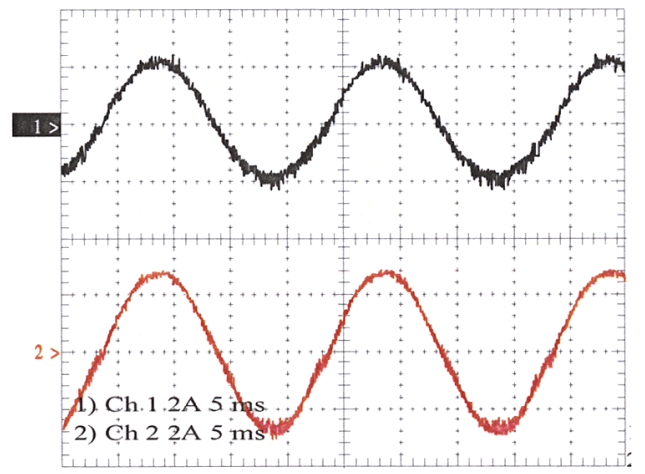

Figure 9. Current at each inverter output without resistor connection. ( $2 \mathrm{~A} / \mathrm{div})$

After the resistor connection for the same non-identical IGBT's the currents at the two inverters output is shown in Figure 10. The phase voltage and current are shown in Figure 11

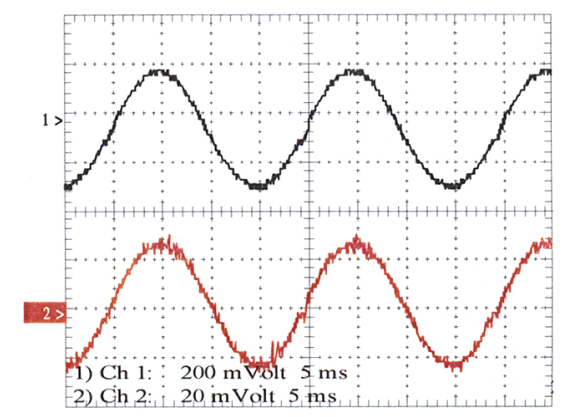

Figure 10 current at each inverter output with resistor connection. (2 $\mathrm{A} / \mathrm{div})$

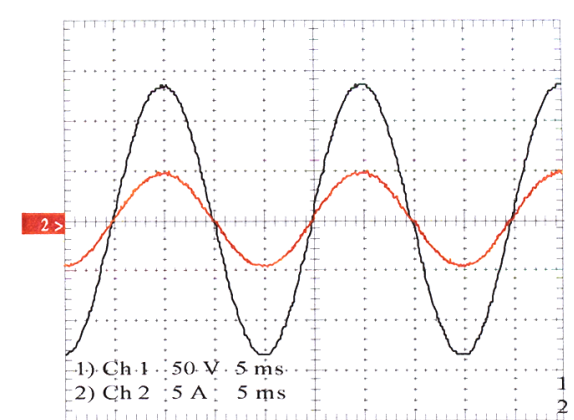

Figure 11 Phase voltage $(50 \mathrm{~V} / \mathrm{div})$ and phase current $(5 \mathrm{~A} / \mathrm{div})$ on the load side

With the connection of two inverters in parallel the total harmonic distortion (THD) on the output voltage and current is less than single inverter. Table 1 shows the harmonic distortion in each case using the phase voltage and phase current. 
Table1. Current and Voltage total harmonic distortion comparison between parallel inverters and single inverter.

\begin{tabular}{|l|l|l|}
\hline & Current THD & Voltage THD \\
\hline Single inverter & $1.35 \%$ & $0.90 \%$ \\
\hline $\begin{array}{l}\text { Two inverters in } \\
\text { parallel }\end{array}$ & $1.04 \%$ & $0.82 \%$ \\
\hline
\end{tabular}

\section{CONCLUSION}

This paper presents a Parallel connected three-phase inverter supplied from low voltage source. The configuration is suitable for fuel cell power source. The improvement of parallel connection over single inverter is clearly shown by finding the THD in each case. The two inverters are sharing the same current value which reduces the circulating current to minimum.

\section{REFERENCES}

[1] Devgan, S.S.; "Impact of environmental factors on the economic evaluation of renewable energy alternative generation"18-20 March 2001 pp. 123 - 126

[2] W. L. Gore \& Associates, "Advanced Power Assemblies for Polymer Electrolyte Fuel Cells: Portable Power"; Proceedings of PORT ABLE FUEL CELLS (felix $n$. buechi, editor). European fuel cell forum, ch-5452 oberrohrdorf, switzerland (june 1999)

[3] I. J. Pitel, S. N. Talukdar, and P. Wood, "Characterization of Programmed-Waveform Pulse-Width Modulation," IEEE Transactions on Industry Applications, Vol. IA-16, Sept./Oct. 1980, pp. 707--715.

[4] Fainan A. Magueed, and Jan Svensson, "Control of VSC connected to the grid through LCL filter to achieve balanced currents," in Proc. IEEE Industry Applications Society Annual Meeting 2005, vol. 2, pp. 572-578

[5] N. Mohan, "A Novel Approach to Minimize LineCurrent Harmonics in Interfacing Power Electronics Equipment with 3-Phase Utility Systems", IEEE Trans on Power Delivery, Vol. 8, p1395-1401. July, 1993

[6] Naik. N, Mohan, N. ; Rogers, M. ; Bulawka, "A novel grid interface, optimized for utility-scale applications of photovoltaic, wind-electric, and fuel-cell systems", IEEE Trans on Power Delivery, vol.10, Oct. 1995, pp. 1920-6

[7] Lohner, A.; Meyer, T.; Nagel, A. A new panelintegratable inverter concept for grid-connected photovoltaic systems. ISIE '96. Proceedings of IEEE International Symposium on Industrial Electronics, Warsaw, Poland, 17-20 June 1996, pp. 827-31 vol.2.

[8] Hatziadoniu, C.J.; Chalkiadakis, F.E.; Feiste, V.K. A power conditioner for a grid-connected photovoltaic generator based on the 3-level inverter. IEEE Transactions on Energy Conversion, vol.14, (no.4), IEEE, Dec. 1999, pp. 1605-10.

[9] F. Blaabjerg, Z. Chen, S. B. Kjaer "Power Electronics as Efficient Interface in Dispersed Power Generation Systems", IEEE Transactions on Power Electronics, vol. 19, No 5, 2004.
[10] Y. Xue, L. Chang, S.B. Kjaer, J. Bordonau, T. Shimizu, "Topologies of Single-Phase Inverters for Small Distributed Power Generators: An Overview". IEEE Transactions on Power Electronics, Vol.19, No.5, pp.1305 1314

[11] Cominos, P.; Munro, N. "PID controllers: recent tuning methods and design to specification"; Control Theory and Applications, IEE Proceedings- Volume 149, Issue 1, Jan. 2002 pp. 46 - 53

[12] SIMULINK help

[13] Bin Zhang; Huang, A.Q.; Bin Chen; "A novel IGBT gate driver to eliminate the dead-time effect" Industry Applications Conference, 2005. Fourtieth IAS Annual Meeting. Conference Record of the 2005, Volume 2, 2-6 Oct. 2005 pp. $913-917$

Mr. Mahmoud A. A. Younis was born in Gaza, Palestine. He receives the B.Sc. degree from IIT, Bangladesh in 1997, and the M.Sc. degree from UM Malaysia. in 2001. Currently he is a lecturer in the Department of Electrical Engineering, university industry selangor (UNISEL), Malaysia, and he is doing PHD in the Department of Electrical Engineering, UM, Malaysia . Mr. Mahmoud is active in Power Electronics research Group in UM and His research interest including, Power Electronics, Industrial Electronics and Fuel cell system

Prof. Dr. Nasrudin Abd Rahim received the B.Sc(Hons) in Electrica and Electronics Engineering and M.Sc (Electrical Power Engineering) degrees from University of Strathclyde, U.K in 1985 and 1988 respectively. He received the Ph.D from Heriot-Watt University, U.K in 1995. He is currently a Professor in the Department of Electrical Engineering, University of Malaya and headed the Center for Research Power Electronics \& Drives, Automation and Control. He has conducted research and advanced development of power converters for the three-phase flyback voltage isolation, ac and dc motor drives, active power filter design, utility interactive photovoltaics, battery charger and energy efficiency application. $\mathrm{He}$ is the author of more than 100 publications concerning power electronics and motor drives. He is a qualified Chartered Engineer and a cooperate member of The Institutions of Electrical Engineers (U.K). He is also a member of the Institute of Electrical and Electronics Engineers IEEE. He is research interests include power conversion techniques, high power PWM converters, modeling and control of power converters, energy efficiency and electrical drives control.

Associated Prof. Dr. Saad Mekhilef received the B. Eng. degree in Electrical Engineering from University of Setif in 1994, and Master of Engineering science and $\mathrm{PhD}$ from University of Malaya 1998 and 2003 respectively. He is currently a lecturer at Department of Electrical Engineering; University of Malaya and he is the deputy director for the Center for Research Power Electronics \& Drives, Automation and Control Dr. Saad is the author and co-author of more than 60 publications in international journal and proceedings. He is actively involved in industrial consultancy, for major corporations in the power electronics projects. His research interests include industrial electronics, power conversion techniques, control of power converters, renewable energy and energy efficiency 